\title{
Back to the basics: Identifying and addressing underlying challenges in achieving high quality and relevant health statistics for indigenous populations in Canada
}

\author{
Janet Smylie ${ }^{\mathrm{a}, \mathrm{b}, *}$ and Michelle Firestone ${ }^{\mathrm{c}}$ \\ ${ }^{a}$ Well Living House Action Research Centre for Indigenous Infant Child and Family Health and Wellbeing, Centre \\ for Research on Inner City Health, St. Michael's Hospital, Toronto, ON, Canada \\ ${ }^{\mathrm{b}}$ Department of Family and Community Medicine, Dalla Lana School of Public Health, University of Toronto \\ CIHR Applied Public Health Chair in Indigenous Health Knowledge and Information, Toronto, ON, Canada \\ ${ }^{\mathrm{c}}$ Well Living House Action Research Centre for Indigenous Health and Wellbeing, Centre for Research on Inner \\ City Health, St. Michael's Hospital, Toronto, ON, Canada
}

\begin{abstract}
Canada is known internationally for excellence in both the quality and public policy relevance of its health and social statistics. There is a double standard however with respect to the relevance and quality of statistics for Indigenous populations in Canada. Indigenous specific health and social statistics gathering is informed by unique ethical, rights-based, policy and practice imperatives regarding the need for Indigenous participation and leadership in Indigenous data processes throughout the spectrum of indicator development, data collection, management, analysis and use. We demonstrate how current Indigenous data quality challenges including misclassification errors and non-response bias systematically contribute to a significant underestimate of inequities in health determinants, health status, and health care access between Indigenous and non-Indigenous people in Canada. The major quality challenge underlying these errors and biases is the lack of Indigenous specific identifiers that are consistent and relevant in major health and social data sources. The recent removal of an Indigenous identity question from the Canadian census has resulted in further deterioration of an already suboptimal system. A revision of core health data sources to include relevant, consistent, and inclusive Indigenous self-identification is urgently required. These changes need to be carried out in partnership with Indigenous peoples and their representative and governing organizations.
\end{abstract}

Keywords: Indigenous health measurement, indigenous health data and data systems, racial and ethnic identification in health data, misclassification

\section{Introduction}

Canada stands out among globally affluent countries with respect to infrastructure deficiencies in Indigenous population health information [1]. These deficiencies result in an infringement for Indigenous peo-

*Corresponding author: Janet Smylie, Centre for Inner City Health, St. Michael's Hospital 30 Bond Street, Toronto, ON, M5B 1W8, Canada. E-mail: janet.smylie@utoronto.ca. ples in Canada of the internationally recognized "right to be counted" [2]. Practically, the resulting gaps in information present a substantive barrier for Indigenous community leaders, health policy makers and practitioners responsible for the implementation and evaluation of evidence based health interventions such as vaccinations, healthy lifestyle programming, and primary care enhancements - interventions that are known to dramatically reduce morbidity, mortality, and overall health care expenditures [3]4]. This situation is in ten- 
sion with an otherwise excellent international reputation with respect to socio-economic and health statistical methods and systems. In Canada, critical health assessment and monitoring information that is taken for granted by the large majority of Canadians, including population level tracking of the incidence course and risk factors related to acute and chronic disease, is simply not available or of substandard quality for Indigenous people. The lands now known as Canada have been home to diverse and flourishing populations of Indigenous peoples for over 15,000 years [5]6]. Prior to European colonization, the linguistic diversity of the Indigenous peoples of the Americas, if one considers root language density, was ten-fold that of Eurasia [7]. Europeans brought with them infectious diseases for which the Indigenous populations had no immunity, and this resulted in devastating declines of Indigenous populations [8]. By the early 1800's, increasing European immigration pressure and a desire by these immigrants to establish permanent farming settlements as the fur trade declined, combined with a resolution of conflict between the United States and Britain resulted in a set of explicit governmental policies, including the Indian Acts, aimed to displace and assimilate Indigenous peoples [8]9]. These policies included forced community relocations, the abduction of Aboriginal children to residential schools, and the outlawing of Aboriginal cultural practices [9]. While these historic colonial policies were ineffective with respect to undermining the unique social values of Indigenous people and their desire to be recognized as distinct and self-determined nations [8], the direct and indirect impacts on health determinants and health status are unfortunately persistent and pervasive [1011]. For example, despite existing data gaps and deficiencies, infant mortality rates for Indigenous populations in Canada are documented to be 1.9 to 3.6 times higher compared to non-Indigenous comparison groups [12] and chronic diseases such as diabetes are epidemic in many Indigenous communities with documented rates that are 3 to 5 times that of non-Indigenous populations [13]. These and other striking disparities in Indigenous/nonIndigenous health status in Canada are linked to a disproportionate and pervasive Indigenous burden of poverty, unemployment, food insecurity, homelessness and housing insecurity as well as lower rates of high school and post-secondary school completion [14].

In 2011, Statistics Canada estimated that there were 1.4 million Indigenous people in Canada [15] - approximately $4.3 \%$ of the total Canadian population. While direct comparisons of this 2011 statistic to pre- vious census generated Indigenous populations counts must be made with caution, there is good evidence from the 2006 and 2001 census that the Indigenous population in Canada is growing rapidly [16]. Given the sizeable and increasing population of Indigenous peoples in Canada and the documented, pervasive inequities in health determinants and outcomes, high quality and relevant population health assessment and monitoring information is an urgent priority.

There are two underlying roots to Canada's Indigenous health information challenges: the lack of relevant, consistent, and inclusive Indigenous identity indicators in core population health data sets; and the need for meaningful Indigenous leadership and participation in the governance and management of Indigenous health data. In this paper, both of these core issues are examined in depth. The paper starts with an overview of Canada's core health information sources and systems, which provides the necessary background for the subsequent discussion of the unique data governance and public service issues relevant to Indigenous health data and data systems and a detailing of the deficiencies in Indigenous identification across these data sources and systems. Next, is an analysis of how system deficiencies contribute to Canada's failure to generate strong Indigenous statistics that accurately represent Indigenous health and social inequities. This paper finishes with a discussion of strategies for moving forward over the short and long term, drawing on domestic innovations and international exemplars.

\section{Overview of Canada's core health information data sources and systems}

As a relatively affluent country immersed in information technology, Canada's health information system draws on several core and established sources, including: the census; vital registration systems; primary and tertiary health care utilization records; disease surveillance and registration systems; and national health and social surveys (see Table 1).

The census and national health and social surveys fall under federal jurisdiction and are administered by Canada's national statistics agency, Statistics Canada. Up to and including 2006, there was both a short form and long form census [17|18]. Response rates to the short and long census in 2006 were $96.5 \%$ and $93.5 \%$ respectively [16]. In 2011, the long form census was replaced by a voluntary National Household Survey (NHS). This change was subject to widespread 
Table 1

Overview of Canada's health information data sources and systems

\begin{tabular}{|c|c|c|}
\hline Data source & Level of administration & Coverage \\
\hline Census & Federal: Statistics Canada & $\begin{array}{l}\text { - } 2006 \text { short form Census: basic demographics including sex, } \\
\text { date of birth, marital and common-law status, and first lan- } \\
\text { guage spoken as a child } \\
\text { - } 2006 \text { long form Census: additional } 53 \text { questions answered } \\
\text { by } 20 \% \text { of the population on the topics of citizenship, immi- } \\
\text { gration, ethnicity, Aboriginal identity, mobility, education, } \\
\text { employment and housing } \\
\text { - } 2011 \text { Census restricted to questions previously on the short } \\
\text { form and long form census discontinued, replaced by the } \\
\text { National Household Survey (NHS) }\end{array}$ \\
\hline $\begin{array}{l}\text { National Health and Social } \\
\text { Surveys }\end{array}$ & Federal: Statistics Canada & $\begin{array}{l}\text { - Drew on Census based sampling frame up to and including } \\
2006 \\
\text { - Indigenous sampling relied on the long form Census } 20 \% \\
\text { sub-sample up to and including } 2006 \\
\text { - Post } 2006 \text { population specific sampling with respect to SES, } \\
\text { ethnicity etc. will draw on the NHS }\end{array}$ \\
\hline Vital registration & Provinces and Territories & $\begin{array}{l}\text { - Personal information on births, deaths, stillbirths and mar- } \\
\text { riages }\end{array}$ \\
\hline $\begin{array}{l}\text { Primary and tertiary health } \\
\text { care utilization, Disease } \\
\text { surveillance }\end{array}$ & $\begin{array}{l}\text { Provinces and Territories-administered } \\
\text { in accordance with Health Canada Act } \\
\text { legislation }\end{array}$ & $\begin{array}{l}\text { - Physician billing data, cause specific hospital discharge } \\
\text { data, emergency room admissions, infectious disease report- } \\
\text { ing, cancer databases, diabetes and other chronic disease } \\
\text { databases }\end{array}$ \\
\hline
\end{tabular}

critique from numerous stakeholders, who were concerned about data quality and comparability [18]. The overall response rate to the 2011 NHS was $69.3 \%$ and low response rates resulted in data quality problems and subsequent suppression of data release for census subdivisions containing less than 25,000 people, which comprised $24.7 \%$ of the census subdivisions nationally. Impacts were worse for some provinces and territories, for example in Saskatchewan and the Yukon territory, $42.6 \%$ and $38.5 \%$ of census subdivision data was suppressed respectively [19]. Additional data quality concerns have been raised with respect to reporting of low income measures and for Indigenous populations [20]. Issues regarding Indigenous data quality are detailed in Section 4.

Vital registration systems are administered by the provinces and territories in Canada, as are primary and tertiary health care utilization data and disease surveillance systems. The provincial/territorial control of health care utilization and surveillance data is in accordance with Canada Health Act legislation, which stipulates that the federal government will provide transfer payments to the provinces and territories to support the universal delivery of government funded hospital and physician health care services to their citizens [21].

The provincial/territorial administration of vital registration and health services creates some jurisdictional variation across the country with respect to derived vi- tal registration, disease surveillance, and health care utilization datasets and statistics. There are a number of national organizations and initiatives that support co-ordination, harmonization and common standards for provincial/territorial data sources. For example, the Vital Statistics Council of Canada, which includes heads of vital statistics from the provincial, territorial, and federal government [22]; the Canadian Institute for Health Information (CIHI), which creates pan-Canadian health information datasets for health care utilization, health care workforce and health expenditures [23]; and linkages of aggregated vital registry data and census data created by Statistics Canada and the Public Health Agency of Canada [24].

At the provincial/territorial level, databases of health care utilization information are organized and linked using individual level identifiers. Commonly, this unique identifier is the provincial/territorial health service registration number, required in order to access government funded health services. Sophisticated systems of data linkage have facilitated the integration of additional sources of health information to these databases in some provinces and territories. For example, the Institute of Clinical Evaluative Sciences (ICES) in Ontario has linked census, national health survey data, CIHI datasets, and disease surveillance registry data to their core provincial health care utilization datasets [25]. 
Finally, at both the national and provincial/territorial levels there have been a series of initiatives to further advance the use of information technologies, including electronic health records (EHR), to enhance direct health service delivery and population health and health care utilization datasets. Canada Health Infoway is a federally funded not for profit organization that has been created to accelerate the development and uptake of EHR in partnership with the provinces and territories [26].

\section{Indigenous governance and management of Indigenous health and social data}

The Indigenous population of Canada is diverse and comprised of multiple culturally, linguistically, kin, and geographically defined subpopulations. The Canadian Constitution Act of 1982 specifies that the Aboriginal Peoples in Canada consist of three groups: Indians, Inuit and Métis [27] and "Aboriginal peoples" is a common collective term used to refer to all of the Indigenous peoples of Canada and their descendants. Increasingly, particularly in the scholarly literature, the term Aboriginal is being replaced with the term Indigenous, as the latter term more clearly references a relationship to a current or historic land base and is not derived from federal government legislation. Indigenous peoples in Canada commonly refer to themselves by their specific tribal affiliation (such as Mi'kmaq, Cree, Innu, Ojibwa) or First Nations, Native, Indian, Inuit or Métis. Textbox A further defines key Indigenous sub-population terms for Canada and Fig. 1 shows 2011 population estimates across core sub-population groups using NHS data.

At the national level, Indigenous peoples in Canada are represented by five National Aboriginal Organizations (NAOs): the Assembly of First Nations (AFN), the Congress of Aboriginal People (CAP), the Inuit Tapiriit Kanatami (ITK), the Métis National Council (MNO), and the Native Women's Association of Canada (NWAC). At the regional and community levels Indigenous peoples in Canada are represented by a complex set of jurisdictionally specific Indigenous governmental and service organizations. At the community level, First Nations people are represented by 617 distinct communities recognized by the federal government as "Indian Bands"; multiple additional distinct First Nations communities that are currently challenging their "unrecognized" status with the government of Canada; and multiple urban Aborigi-

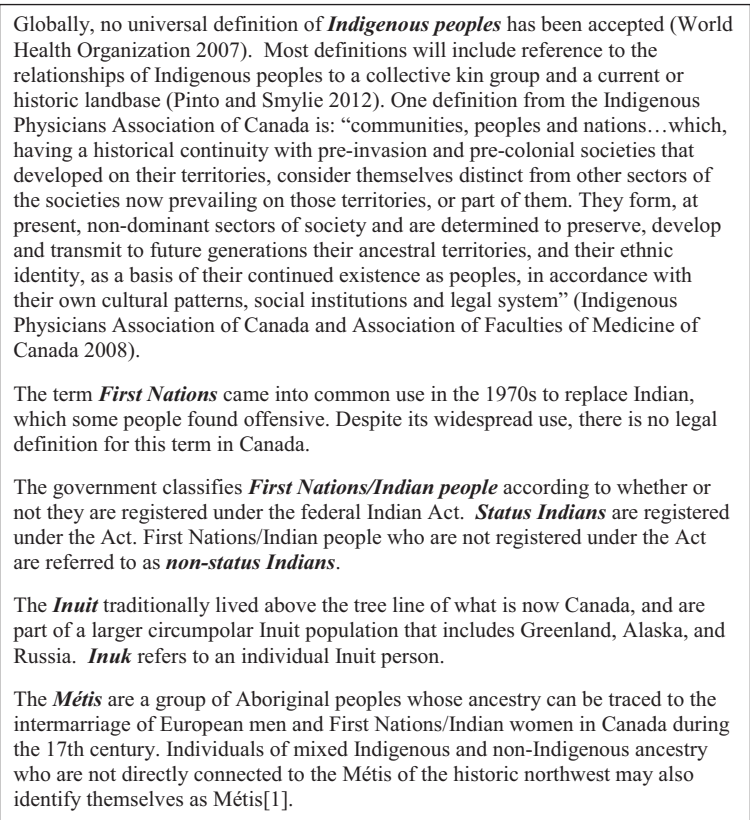

The government classifies First Nations/Indian people according to whether or not they are registered under the federal Indian Act. Status Indians are registered under the Act. First Nations/Indian people who are not registered under the Act are referred to as non-status Indians.

The Inuit traditionally lived above the tree line of what is now Canada, and are part of a larger circumpolar Inuit population that includes Greenland, Alaska, and Russia. Inuk refers to an individual Inuit person.

The Métis are a group of Aboriginal peoples whose ancestry can be traced to the intermarriage of European men and First Nations/Indian women in Canada during the 17 th century. Individuals of mixed Indigenous and non-Indigenous ancestry who are not directly connected to the Métis of the historic northwest may also identify themselves as Métis[1].

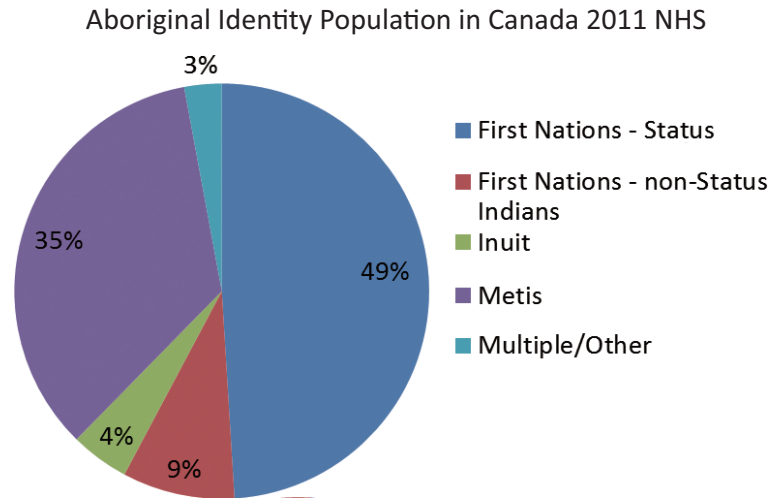

Fig. 1. Core Indigenous Population Groups in Canada (NHS 2011). Total Aboriginal population $=1.4$ million people or $4.3 \%$ of total Canadian population. (Colours are visible in the online version of the article; http://dx.doi.org/10.3233/SJI-150864)

nal organizations and service providers. Regional and provincial/territorial First Nations tribal councils are comprised of member First Nations communities and First Nations together come together to form the AFN. The Inuit are represented by four land claim regions: Nunatsiavut (Labrador), Nunavik (northern Quebec), Nunavut, and the Inuvialuit Settlement Region in the Northwest Territories. These four regions are together known as the Inuit Nunangat and similarly collectively comprise the ITK. There are also Inuit specific regional and community organizations, such as the Inuit Tungasavvingat in Ottawa that provide services to Inuit living outside of these northern Inuit regions. Métis have 
local community councils which fall under the umbrella of provincial/territorial Métis governing organizations in most parts of Canada, which in turn come together to form the MNC. CAP has a number of provincial and territorial affiliates, which come together to represent off-reserve, non-status, and status Indians, Métis and southern Inuit peoples living in urban, rural remote and isolated areas throughout Canada. The provincial/territorial affiliates of NWAC support community level "local" groups of Indigenous women. In addition, there are multiple health and social service organizations, particularly in urban areas. Some of these may have originated at the community level, but are now represented by provincial/territorial and national umbrellas. For example, there is a strong network of community level "Friendship Centres" across cities and towns, which are represented by regional provincial/territorial organizations, which in turn are represented by the National Association of Friendship Centres.

Indigenous governing and organizational stakeholders in Canada from across these national, regional, and community level groups have clearly articulated their desire to participate in the governance and management of their knowledge and information system [29. 31]. For many, this is seen as an important aspect of the inherent right to self-determination [31-33]. The mandate for Indigenous leadership in the governance and management of their health and social data is supported by international laws and covenants regarding the rights of Indigenous peoples to self-determine their knowledge systems and health and social services, including the International Declaration on the Rights of Indigenous Peoples, and domestic Indigenous policy recommendations including the findings of the Royal Commission on Aboriginal Peoples [34-36].

The ethics and rights based policy platform with respect to Indigenous leadership and participation in the collection, interpretation and use of Indigenous health information has emerged partially in response to historic and current abuses of health information derived from Indigenous individuals and communities. These include for example, the collection of health assessment data from malnourished Indigenous children in residential schools as part of federally sponsored nutritional experiments conducted in the 1940's and 50s, [37] and more recently, the unauthorized use of genetic information derived from the blood samples of members of the Nuu-chah-nulth First Nations in British Columbia by Health Canada funded researcher Dr. Richard Ward in the 1980's [38]. Practi- cally, emerging Indigenous health policy and service research provide evidence that Indigenous leadership and participation in Indigenous health information systems is essential to ensuring that measures are policy and practice relevant and that outputs will be applied [39. 41].

Legally, Indigenous rights, including an Indigenous right to health as distinctly understood and expressed by specific Indigenous groups, are entrenched in section 35 of the 1985 Canadian Constitution [42]. The Constitution also entrenches a governmental "duty to consult" Indigenous peoples prior to enacting any legislation, regulation or potential infringement upon established or potential Indigenous rights and to make appropriate accommodations [4344]. Grand-Chief Matthew Coon Come has described Canada's repeated failures to uphold this duty to consult as a violation of the Canadian Constitution and international law [45]. In addition to these inherent Constitutional rights to health and health care, which apply inclusively to First Nations, Indian, Métis and Inuit peoples, First Nations persons whose ancestors signed treaties possess supplemental treaty rights to health and health care, based on promises made during treaty negotiations. If health assessment and response are recognized as an integral part of health and healthcare, one can make a legal argument that the assurance of adequate and relevant Indigenous health assessment and response is an underlying and inherent governmental responsibility that takes precedence over any legislation or policies subsequent to the Canadian Constitution. Further, the Constitutional duty to consult, imposes a legal requirement to actively involve Indigenous peoples in the planning, implementation, and evaluation of Indigenous health assessment and response, to ensure that it is aligned with the underlying Indigenous right to health and Indigenous rights more broadly.

Despite expanding scholarship and related ethical, legal, and policy recommendations that challenge the historic and ongoing marginalization of Indigenous peoples in the planning, implementation, and ongoing management and governance of Indigenous health information systems [46-50], substantive Indigenous participation continues to be the exception rather than the norm. The first author's systematic review of Indigenous involvement in Indigenous health information systems in Canada and internationally [51|52] identified some advances both domestically and globally, but also important gaps. Serious deficits were identified in the development of local and regional health information systems, feedback of health infor- 


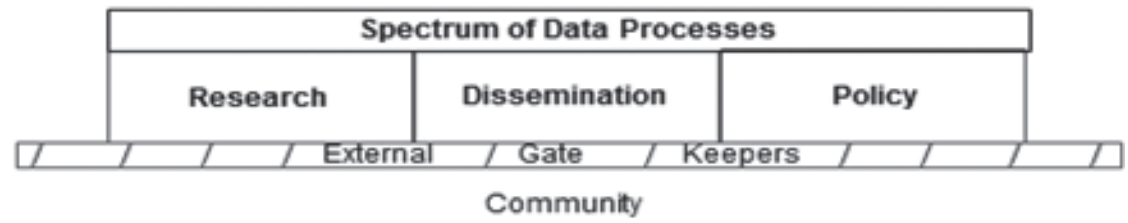

Fig. 2. Data and data systems that reinforce community marginalization.

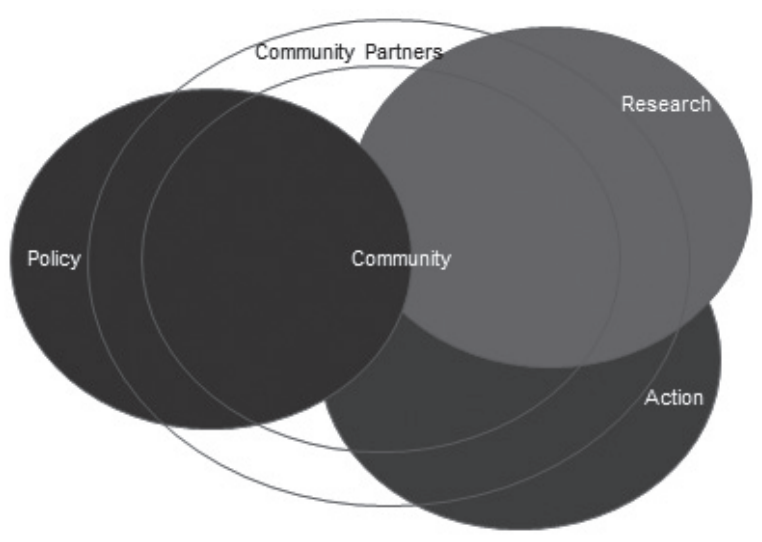

Fig. 3. Data and data systems that support community self-determination.

mation to these systems, and the processes of Indigenous input into these systems, including the application of Indigenous-specific frameworks and indicators [51]. These findings are not surprising since the large majority of policy makers, practitioners and researchers involved in the development of population health datasets have had limited exposure to Indigenous peoples and their diverse systems of knowledge and practice with respect to health.

In order for health data to become a tool for Indigenous social empowerment and social change, the social structuring of data governance and management must change from systems that reinforce social exclusion by marginalizing systematically disadvantaged populations from their data, to systems in which they are fully and centrally involved in data decision making [5354] (Figs 2 and 3).

Clearly negotiated and properly implemented data partnerships and data sharing agreements can be a key tool in the shifting of data governance and management relationships towards one of Indigenous community leadership and participation. The governing structure of the Our Health Counts (OHC) project, a study aimed at developing a baseline population health database for urban Indigenous people living in Ontario, was operationalized through a Governing Council comprised of representatives from key Provincial Indigenous orga- nizations, research agreements and data management and governance protocols [55]. This included successfully negotiated community research agreements with each of the three community project sites and a tri-party data sharing agreement, which was negotiated between the Institute of Clinical and Evaluative Sciences (ICES), the OHC Governing Council and St Michael's Hospital. Success of the OHC project included strong Indigenous community partnership and participation, and the production of previously unavailable and highly policy and practice relevant urban Indigenous health statistics. These successes were facilitated through mutually supportive partnerships and a clear research governance model, as well as through the pursuit of research methods that built on the strengths of urban Indigenous communities [56]. Another example is the Health Governance Structure of the First Nations Health Authority (FNHA) in British Columbia (BC) [57]. The signing of the British Columbia Tripartite Framework Agreement on First Nations Health Governance between BC First Nations, the province of $\mathrm{BC}$ and the Government of Canada marks a significant shift in the delivery of health services and will enable First Nations in BC to participate fully in all decision making processes at institutional, provincial, regional and local levels [58].

Engagement of Indigenous communities in the collection and analysis of their health data is also essential to ensuring that indicators and measurement tools are aligned with Indigenous community concepts of health and social well-being. Indigenous understandings of health are diverse and can differ from the concepts underlying commonly used health indicators and measurement tools [53]. For example, measures of disease specific morbidity and mortality are a central component of existing health status reporting. These statistics are generally recognized as important by Indigenous scholars and policy makers, however there is an accompanying critique regarding their "unbalanced" use. There is concern that the use of such "deficitbased" indicators in isolation perpetuates the marginalization of local Indigenous theories of health which may incorporate for example notions of balance, pos- 
itivity, well-being, and inter-relationality at a foundational level [59-62]. Furthermore, Indigenous scholars and policy-makers argue that the widespread use of deficit based measures has negative implications for Indigenous individuals and communities as they can perpetuate negative stereotypes and become internalized and contribute to internalized negativity and racism [63 64].

In response to these concerns, Indigenous organizations in Canada have developed their own culturally specific health indicator frameworks. For example, ITK has been actively developing their own health information systems, starting with the Inuksiutiin Health Information Framework in 2002 and currently with Naasautit: Inuit Health Statistics [65]. Métis regions across the country have also been working on health information systems development, with Métis specific provincial health surveys (convenience samples) completed in BC and Saskatchewan and linkages with provincial health data bases in Manitoba and Ontario 6667].

Globally, Indigenous scholars and policymakers have recommended an approach that incorporates Indigenous specific measures to complement more universally accepted measures [516869]. There are a number of recent survey initiatives in Canada that have adapted this approach, including the Aboriginal Children's Survey [70], the Inuit Health Survey [71], the Our Health Counts Survey [72] and the First Nations Regional Longitudinal Health Survey [73].

The First Nations Regional Longitudinal Health Survey (RHS) is an exemplar both with respect to Indigenous governance and management of health data and with respect to the indicators and measurement tools that are relevant and useful to the Indigenous individuals and populations whose data is being gathered. The RHS was initiated in 1997 to address the exclusion of Aboriginal peoples from national surveys. Currently it is the only First Nations governed national health survey in Canada and the only national survey for First Nations on-reserve populations. It has been successfully implemented in First Nations communities across the country in 2002/2003 and 2008/2009. It collects information based on both Western and traditional First Nations understandings of health and wellbeing and is a progressive model of First Nations governance and management of health information. As highlighted in the RHS cultural framework, all aspects and components of First Nations health and well-being are integrally interconnected within the web of life and living. This includes physical, mental, emotional and spiritual health as well as a healthy lifestyle, cultural continuity with the past and future opportunity and a healthy connection to culture, family and community. Therefore, First Nations interpretation and analysis of health outcomes cannot be categorized or isolated from one another as each of these concepts impinges on the other in significant ways [74].

This issue of Indigenous community engagement in research, evaluation and policy studies based on secondary data analysis of existing federal or provincial/territorial data holdings is important to raise because it is an important application of these datasets, however there is considerable variation with respect to the interpretation and application of existing ethical guidelines. While the persons conducting secondary data analysis may be initially more distanced from the Indigenous communities whose data is being used, compared to study involving primary data, secondary data analysis is not exempt from potentially harming Indigenous individuals and communities, particularly if we consider the issues raised earlier regarding the potential harms of deficit based reporting. The Tricouncil Guidelines for Research Involving Humans [49], to which the large majority of scholarly institutions in Canada adhere, stipulates that in situations where researchers are using publically or legally available datasets to conduct secondary data analysis, REB review may not be required, but "researchers should seek culturally informed advice before the use of such data to determine if harms may result and if other considerations, such as sharing of the research results, should be explored with the original source community" [49]. Secondary data analysis research involving non-publically or legally available datasets and/or data linkages which result in newly identifiable Indigenous datasets, require research ethics review board (REB) review and consequently evidence of Aboriginal community engagement. While it is standard practice for researchers involved in primary data collection and analysis with Indigenous communities in Canada to describe the specifics of Indigenous community engagement and participation in the research study within their scholarly publications, this information is typically excluded from publications involving secondary data analysis. For example, the three most recent research publications on Indigenous health published in Canada's highest impact health journal, the Canadian Medical Association Journal (CMAJ) were population based epidemiologic analyses of Indigenous/nonIndigenous disparities in the management of acute myocardial infarction, risk of progression to end-stage re- 
Table 2

Indigenous Identity Information in Primary Populations Health Data Sources, Canada

\begin{tabular}{|c|c|}
\hline Data Source & Indigenous Identifier \\
\hline Census & No - removed in 2006 \\
\hline Vital Registration & $\begin{array}{l}\text { On birth registration in the majority of provinces and territories; on death registration in fewer provinces and } \\
\text { territories; inconsistent terms and poor data quality }\end{array}$ \\
\hline $\begin{array}{l}\text { Primary Care/ } \\
\text { Hospitalization Records }\end{array}$ & $\begin{array}{l}\text { No - a few provinces/territories have Indigenous identifiers on their health cards which are generally not used } \\
\text { due to poor quality of these flags }\end{array}$ \\
\hline $\begin{array}{l}\text { Disease Surveillance/ } \\
\text { Registries }\end{array}$ & Limited; Inconsistent terms \\
\hline $\begin{array}{l}\text { National Health and Social } \\
\text { Surveys }\end{array}$ & $\begin{array}{l}\text { Yes on some - loss of population based sampling frame with Indigenous identity flag post 2006; large majority } \\
\text { are significantly underpowered in their Indigenous sample and exclude First Nations on-reserve communities }\end{array}$ \\
\hline
\end{tabular}

nal disease and death among diabetics, and progression to kidney failure according to presence and severity of albuminuria respectively [75-77]. All three studies relied on secondary data analysis involving a crosslinkage between federal Indian registration records as defined by the Indian Act with provincial health databases to identity the Indigenous cohort. While all 3 studies report research ethics board approval from university REBs and all three studies have important policy implications for the First Nations populations whose data are used in the studies, none of these studies describe any type of First Nations community engagement with respect to study design, interpretation, and dissemination. This unfortunate gap leaves the reader uncertain as to the underlying ethics and methods of these studies and represents a missed opportunity to support the shift towards research processes and outcomes that are relevant and useful to the Indigenous communities whose data are being used.

This section has introduced some important background information about the Indigenous peoples and their representative governing bodies and organizations in Canada; ethical, right-based, and practical justifications for shifting towards Indigenous led governance and management of Indigenous health information; key strategies for moving forward ; and ongoing challenges. The relationship of individuals and identifiable communities to their data, including issues of privacy, informed consent, data governance and management is an area that is highly relevant not only for Indigenous health information, but for statistics more generally. It is complex and draws heavily on the fields of ethics, social theory, community engagement, governance, and law - disciplines that are not typically core content in the training of statisticians. It is our hope to stimulate further inquiry and discussion among our colleagues about data governance both with respect to Indigenous populations in Canada and more generally. Global trends towards increasing the use of linked administrative datasets and "big data" risk further distancing already marginalized individuals and communities from active leadership and participation in the decision making regarding the use of their data - making the need for further work in this area an urgent priority.

\section{The absence of relevant, consistent, and inclusive Indigenous identifiers in core population health data sources}

The core problem with Canada's Indigenous health information infrastructure is that none of the primary population health data sources consistently, inclusively, or reliably gather Indigenous identity information (Table 2). In this section, we begin with an overview of the jurisdictional complexities of Indigenous health service delivery in Canada, which fundamentally impact Indigenous health information systems. We then describe the current state of census, survey, vital registration, health care utilization, and disease surveillance systems in Canada with respect to Indigenous identifiers. This is followed by a discussion of Indigenous self-identity as the gold standard for Indigenous identification and a review of the underlying practical and rights-based rationales for Indigenous identification in core data sets.

\subsection{Jurisdictional complexities and the need for disaggregated datasets}

As described in the preceding section, the Indigenous population of Canada is actually comprised of multiple culturally, linguistically, and politically distinct subpopulations. Healthcare services in Canada overall, fall under provincial/territorial jurisdiction and are increasingly planned and delivered at the small regional and local level. For Indigenous peoples in 
Canada there are additional federal governmental, constitutional and treaty responsibilities for the provision of health and health care and the federal government directly funds some Indigenous specific health programming and services, which are differentiated and streamed according to historic and current federal policies, including the Indian Acts. For many decades there has been partial recognition and policy responses regarding the federal responsibility to support the rights of First Nations people recognized under the Indian Act and Inuit peoples to health and health care services. Currently, programming and services for these groups fall under the First Nations and Inuit Health (FNIH) of Health Canada. Non-Status First Nations/Indian and Métis peoples in contrast have been primarily excluded from federal Indigenous health programming and services (despite their entrenched inherent constitutional rights) and currently jurisdiction for these groups fall primarily under the Public Health Agency of Canada (PHAC).

These historic and current jurisdictional complexities are at the root of many of the existing Indigenous data systems deficiencies and double standards. For example, provincial/territorial health and public health departments, to various extents, have argued that historically and currently, Indigenous health, including Indigenous health surveillance, is a federal responsibility. The subsequent result is the underdevelopment of Indigenous health information systems at the provincial/territorial level. When provinces and territories have included Indigenous identifiers in their health information systems, the provincial/territorial administration of health services and health surveillance more generally has resulted in significant provincial/territorial inconsistencies in the terms of Indigenous identification and data processing protocols. The federal government, historically and currently has focused on the development of health information systems almost exclusively for First Nations persons with status living in First Nations on-reserve communities and Inuit living in the Inuit Nunangat, leading to an almost complete exclusion of non-Status First Nations/Indian, Métis, and urban Indigenous populations from the majority of federal and provincial health information systems.

The other key consequence of these jurisdictional complexities and the trend towards local and small regional health service planning and delivery, is that national level, pan-Indigenous data sets are of little practical utility. The health needs and existing health services and programs available to First Nations persons living in on-reserve First Nations communities, nonStatus First Nations/Indians, Métis, and Inuit are distinct. Even within these core sub-population groups there is tremendous variability in health needs depending on the local contexts. Geography, including whether or not individuals and communities are urban, rural, or remote, also has a major impact on health needs and available health services and programs. For all of these reasons, there is a need to move towards Indigenous data systems that can be disaggregated to provide valid estimates of core population health indicators for First Nations persons living in onreserve First Nations communities, First Nations persons living off-reserve, non-Status First Nations/Indian people, Inuit, Métis, and urban Indigenous peoples. These disaggregated estimates are needed at the subprovincial and ideally local health planning and service delivery level.

\subsection{Census and national Household survey}

Counts of Aboriginal people in Canada predate confederation [78, 80]. Aboriginal ethnicity data was included in the Canadian Census from the first national census in 1871 up to and including 2006 [80]. Aboriginal ethnicity questions were gradually refined between 1981 and 1996. In the 1981 census, multiple ethnic origins were allowed for the first time and in 1986 there was a change in the ethnic origin question from the 1981 question of, "to which ethnic or cultural group did you or your ancestors belong on first coming to this continent?" to "To which ethnic or cultural group(s) do you or did your ancestors belong?", which is better aligned with Indigenous identity. In 1996, a specific question regarding Aboriginal identity was added to the Census: "Is this person an Aboriginal person, that is, North American, Indian, Métis or Inuit (Eskimo)?" which, for the first time, allowed for population counts which reflected Aboriginal identity in addition to Aboriginal ancestry [80].

Quality issues with the 2001 and 2006 census data for Indigenous populations include significant block non-participation by First Nations on-reserve communities; [81] undercounting of homeless and highly mobile populations (both of which are over-represented in Aboriginal populations); non-participation by Aboriginal people for a variety of additional reasons including a distrust of and/or political disagreement with federal governmental agencies and accessibility with respect to assumed literacy levels. Finally, some Aboriginal people may participate in the census but not 
share their Aboriginal identity and/or ancestry information [51|52|82]. This may be more common for some subpopulations of Aboriginal people. For example, there was a large increase in the Métis identity population between the 2001 and 2006 census, which could not be accounted for solely by population growth. This has been linked to an increase in the number of Métis who self-identified as Métis in the 2006 compared to the 2001 census [83].

There is recent evidence that census non-participation in urban areas by Indigenous populations may be especially significant. For example, a health assessment of Inuit living in the City of Ottawa conducted in 2010 using respondent driven sampling found that only $18 \%$ (12.2-26.2) of this self-identified Inuit population reported participating in the 2006 census [84 85].

Despite these limitations, up until 2006, the census uniquely provided essential information that was often not available elsewhere, regarding the size of the total Indigenous population and multiple Indigenous sub-populations (including self-identified First Nations people with status, non-status First Nations/Indian people, Inuit, Métis, and urban Indigenous people), family structure, geographic distribution, language use, and the social determinants of health (i.e. income, employment, housing adequacy, education). Importantly, it also provided the ability to compare Indigenous populations to non-Indigenous populations allowing for the quantification of health equity gaps.

The transfer of Indigenous identity and ancestry questions from the mandatory long form census to the voluntary national household survey (NHS) in 2011 substantively weakened an already suboptimal foundation for Indigenous statistics in Canada as the response rate of the NHS is significantly lower than that of the 2006 long form census (68.6\% compared to $93.5 \%$ ). Subsequent data quality issues have been identified for estimates of low-income prevalence, geographic areas with small populations (i.e. census subdivisions with fewer than 25,000 people) [86], and specific Indigenous subpopulations [87].

The big change with respect to the Indigenous data available from the 2011 NHS compared to the 2006 census is that Indigenous data is no longer available for almost all census subdivisions, some census divisions, and some census metropolitan areas. Furthermore, there is no data release at the health region level as there was with the 2006 census. Statistics Canada non-specifically annotates that for suppressed census subdivision, census division, and census metropolitan areas that an Aboriginal profile is not available for the area listed, due to the following reasons: an Aboriginal identity population of less than 250 (the same threshold that was set for the suppression of income data in response to small population data quality issues); data quality or confidentiality reasons; or that the area is comprised of or contains incompletely enumerated Indian reserves or Indian settlements [88]. This data suppression represents a huge step backwards with respect to Indigenous population health surveillance and response in Canada - as detailed in section 4.2 above, it is this smaller regional level reporting that is urgently required for meaningful Indigenous population health assessment and response.

Additional Indigenous data quality problems include incomplete enumeration of 36 "Indian reserves/ Indian settlements" and a suspected overestimation of Inuit population living outside of Inuit Nunangat at the national level. The Inuit estimation is reported as higher and more variable for some smaller geographic areas [86].

\subsection{Other national health and social surveys}

Statistics Canada supports a number of additional national health and social surveys which draw on a census-based sampling frame. Aboriginal people are typically excluded or under-sampled in these studies. For example, for political reasons, First Nations people living on reserve are excluded from major national health studies such as the Canadian Community Health Survey (CCHS) [89], the National Longitudinal Child and Youth Survey (NLCYS) [90], and the Canadian Maternity Experiences Survey (MES) [91]. For many decades up to and including 2006, the Canadian census was comprised of a short form and a long form. The long form had additional questions not found on the short form and was delivered to a $20 \%$ subset of the total population. In order to generate a representative sample of Aboriginal people, prior to 2011, national health surveys such as the CCHS, NLCYS, and MES drew on the $20 \%$ population sample generated by the long form census. Unfortunately this $20 \%$ subsample did not provide adequate numbers of potential Aboriginal participants to adequately power these studies so that they could provide quality estimates disaggregated by Aboriginal subpopulation (i.e. First Nations, Inuit and Métis specific data sets) at geographic levels smaller than the provinces and territories.

These gaps have been partially addressed by the development and implementation of the Aboriginal Peoples Survey, which has been delivered nationally to 
Aboriginal people (excluding First Nations people living on reserve) by Statistics Canada in 1991, 2001, 2006 and 2011 [20]. An Aboriginal children's survey was also developed and administered to caregivers of Aboriginal children (excluding First Nations children living on reserve) in 2006 [92]. There has been increasing partnership in the development and implementation of these tools with national Aboriginal organizations and Aboriginal scholars over time. The 1991, 2001, and 2006 Aboriginal peoples and Aboriginal children's surveys used census based sampling frames, which will significantly under-sample urban Aboriginal people who are homeless, highly mobile, have lower levels of educational achievement in written English or French, or who do not want to participate in the census for personal or political reasons [55 84|85|93]. These sampling issues are exacerbated in the 2011 Aboriginal Peoples Survey, which drew its sampling frame from the NHS, since there was no Aboriginal identity or ancestry question on the 2011 census. The Aboriginal children's survey was not repeated in 2011, resulting in the exclusion of Aboriginal children between the ages of 0-5 from Statistics Canada's Aboriginal specific surveys.

\subsection{Vital registration records, health care utilization datasets, and disease surveillance and registration systems}

A review of provincial/territorial birth registration conducted in 2008 [94] revealed that 5 of the 13 provinces/territories collected no information regarding Indigenous identity. One province asked generally about Aboriginal identity, 6 provinces/territories asked about First Nations or Indian identity (using inconsistent terminology), 4 provinces/territories asked about Inuit identity (though 2 of these until recently used the misnomer "Eskimo"), and 3 provinces/territories asked about Métis identity. One province (Quebec) collected Indigenous identity information indirectly by asking about maternal language which is a poor proxy for Indigenous identity, particularly in urban areas where the large majority of Indigenous peoples don't report an Indigenous language as a mother tongue) [9596. Indigenous identity is typically not recorded at all on death registration, so mortality studies in Canada are dependent on registry linkages [97] or geocoding by density of Indigenous population, using small areas with high prevalence of Indigenous identity populations as a proxy for Indigenous identity [98]. For reasons detailed in section
5 below, both of these methods will almost always under-estimate Indigenous health challenge and subsequently Indigenous/non-Indigenous health disparities. Both methods also have substantive coverage issues as they are restricted to specific Indigenous subpopulations. The linkage method will only include the specific Aboriginal subpopulation for which registries that can be linked exist, and the use of geocoding as a proxy for Indigenous identity only works for areas where there is a high prevalence of Indigenous peoples (once again excluding most urban, Métis and nonStatus populations) and estimates will almost always under-estimate, particularly for relatively rare events.

With respect to health care utilization data, Indigenous identification is currently not available in primary source data files. This is because in Canada, information regarding ethnicity and/or race is not routinely collected at point of service access (i.e. emergency room or hospital admission or primary care service rostering) as it is in many other countries. A few provinces and territories have flags that identify First Nations people with status as part of information included in health service registration however this data is generally not used due to poor sensitivity.

Disease surveillance systems, including disease registries are limited with respect to inclusion of information regarding Indigenous identity. This is because they either do not include information regarding Indigenous identity, gather information only from specific sub-populations of Indigenous peoples or use inconsistent terminology across provinces and territories. For example, during the H1N1 outbreak in Canada, which disproportionately impacted Indigenous individuals and communities, the adjoining provinces of Ontario and Manitoba had inconsistent approaches to Indigenous identification on the disease reporting forms, with Manitoba including information on Indigenous identity and Ontario excluding this information. This difference in approaches resulted in a missed opportunity in Ontario to monitor disease outbreak in the $70 \%$ of its Indigenous population living off-reserve. On a positive note, Cancer Care Ontario has been engaging in a series of pilot studies in partnership with Indigenous communities to improve Indigenous identification in cancer registries in the province [99].

\subsection{Indigenous self-identification as the gold standard}

For Indigenous people, being able to define one's own identity, both individually and collectively, on 
one's own terms is a central part of self-determination. Globally, Indigenous self-identification and acceptance of self-identification has been recognized as "an essential component of indigenous peoples' sense of identity" [100]. In New Zealand, the country with the best Indigenous health data infrastructure in the Western hemisphere, self-identification is the recommended method of reporting ethnicity in all collections of official statistics by Statistics New Zealand [101]. A study in the United States demonstrated that race and ethnicity classification on American death certificates which are determined by the funeral director misclassified Native Americans/Alaska Natives as White over $40 \%$ of the time compared to self-report on the Current Population Survey (CPS). For all of these reasons, it is important that self-report be recognized in Canada as the preferred method of Indigenous identification not only in the census, NHS and national health and social surveys, but also in vital registration, health care utilization, and disease surveillance/registry data systems. Methods that have been refined and tested in other affluent countries with minority Indigenous populations such as Australia and New Zealand provide useful exemplars [101-103]. The fluidity of individual and collective Indigenous self-identification over time is an additional complexity that requires ongoing methodologic innovation.

\subsection{The right to be counted}

In this section we have described the jurisdictional complexities that contribute to the underdevelopment of core Indigenous health information data sources in Canada. We have detailed specific strengths and deficits for data sources with a focus on ability to accurately and inclusively identify Indigenous peoples. Overall there is inconsistent and incomplete coverage of the total Indigenous population, with the systematic exclusion of substantive population groups such as non-Status First Nations/Indians, Métis, and urban Indigenous peoples in many instances. These groups comprise $9 \%, 35 \%, 56 \%$ of the total population of Indigenous peoples in Canada respectively. These exclusions can be linked historically to Indian Act legislations, which at the time they were first introduced we deliberately aimed to assimilate Indigenous peoples [8].

The right to be counted is a human right, recognized by the World Health Organization [2]. Ethically and practically the gold standard with respect to Indigenous enumeration is for this to be done using self- identification. Globally, failure to be enumerated has been linked to increased mortality [2]. For Indigenous peoples in Canada, existing data gaps mean a missed opportunity to fully benefit from evidence based interventions including population tailored vaccination, healthy lifestyle programming, and primary care enhancements. With respect to data regarding the health and wellbeing of Indigenous women in Canada, gaps in information have been flagged as problematic by the United Nations Human Rights Council [104 105].

Taking a step back from the immediate Indigenous health data infrastructure limitations we have just described, it is hard to justify an approach to Indigenous population health assessment that commonly systematically excludes over $40 \%$ of the population - particularly in a relatively affluent and technologically sophisticated country like Canada. In the next section, we will further illustrate some of the specific impacts of these Indigenous source data infrastructure deficiencies on the assessment of and response to Indigenous health and social inequities.

\section{How infrastructure deficiencies contribute to the masking of Indigenous health and social inequities in Canada}

The infrastructure deficiencies in the core population health data sources described in the previous section result in a number of methodological problems in the production of derived measures of Indigenous health determinants, health status, and health care access. As already discussed, in many cases, including for example both Indigenous specific measures of health care utilization and disaggregated district health region level demographic, health and social statistics, reliable estimates simply are not available. There is an equally important and perhaps more insidious challenge for situations where we do have derived measures - Indigenous/non-Indigenous misclassification errors and Indigenous non-response bias almost uniformly result in incorrect estimates of Indigenous health measures. Indigenous/non-Indigenous misclassification can be the result of errors in classification in the source dataset (i.e. death registration record) or through the use of suboptimal methods such as linkage to a single registry of a sub-population of Indigenous peoples and/or geocoding in order to determine Indigenous identity because the source dataset doesn't have this information. Indigenous non-response bias occurs when Indigenous health and social surveys use a con- 
venience or non-representative sampling frame. In this section we will detail these problems and demonstrate how systematically they almost always result in an underestimate of Indigenous health and social inequities.

\subsection{Indigenous/non-Indigenous misclassification bias in source datasets}

Indigenous/non-Indigenous misclassification error in the calculation of simple Indigenous event/population ratios can be represented as follows:

$$
\begin{aligned}
& \text { Actual Indigenous Ratio } R=X / Y \\
& \text { Calculated Indigenous Ratio } \\
& R_{1}=(X-a+b) /(Y-c+d) \\
& \text { Error in Indigenous ratio }=R-R_{1} \\
& \text { where } X=\text { Indigenous events; } Y=\text { Indigen } \\
& \text { population at risk; } a=\text { Indigenous events } \\
& \text { classified as non-Indigenous; } b=\text { non-Indigen } \\
& \text { events misclassified as Indigenous; } c=\text { Indigen } \\
& \text { people misclassified as non-Indigenous; } d=\text { non } \\
& \text { Indigenous people misclassified as Indigenous } \\
& \text { Errors in non-Indigenous event/population ration } \\
& \text { can likewise be represented as: } \\
& \text { Actual non-Indigenous Ratio } r=x / y \\
& \text { Calculated non-Indigenous Ratio } \\
& r_{1}=(x+a-b) /(y+c-d) \\
& \text { Error in non-Indigenous ratio }=r-r_{1}
\end{aligned}
$$$$
\text { where } X=\text { Indigenous events; } Y=\text { Indigenous }
$$$$
\text { population at risk; } a=\text { Indigenous events mis- }
$$$$
\text { classified as non-Indigenous; } b=\text { non-Indigenous }
$$$$
\text { events misclassified as Indigenous; } c=\text { Indigenous }
$$$$
\text { people misclassified as non-Indigenous; } d=\text { non- }
$$

Errors in non-Indigenous event/population ratios

In Canada we normally do not have the ability to estimate the magnitude of $\mathrm{a}-\mathrm{d}$ in estimates drawing on a given source of Indigenous identity data, as we are typically reliant on a single Indigenous identifier and there is no "gold standard" or other comparator. However, studies in the United States demonstrate that misclassification of Indigenous events as non-Indigenous is much more common than the misclassification of non-Indigenous events as Indigenous. For example, Arias et al. assessed the validity of race and ethnicity classification on American death certificates, determined by the funeral director proxy report, by comparing to self-report race and ethnicity data collected as part of the Current Population Survey (CPS), a multistage stratified probability sample derived from the US census with a response rate of approximately $95 \%$ [106]. In this study, racial/ethnic misclassification of Native Americans/Alaska Natives as White on the death certificate using CPS self-report as the gold standard was found to be $41 \%$ and $42 \%$ respectively for the periods 1979-1989 and 1990-1998. In contrast there was nearly $100 \%$ agreement between death certificate and CPS self-report for the White population over both periods [106].

With respect to the impact of Indigenous-non Indigenous misclassification of events on the underestimation of Indigenous health disparities, the effect can range from modest to alarming, depending on factors such as the overall frequency of the event, the relative sizes of the Indigenous and non-Indigenous comparator populations, and the relative difference in events between Indigenous and non-Indigenous populations.

Although we typically do not have a data system in Canada that facilitates the estimation of Indigenous/ non-Indigenous misclassification with precision we can begin to estimate the potential impacts on the quality of Indigenous health measures by setting some assumptions. Indigenous infant mortality rates in Canada is one area where there has been ongoing discussion with respect to the quality and magnitude of reported Indigenous rates [107-109]. While these issues of inconsistent or absent identification of Indigenous birth registration systems precludes the calculation of panCanadian Indigenous infant mortality rates, peer reviewed studies have revealed IMR rates that are $190 \%$ higher for First Nations compared to non-First Nations and $360 \%$ higher for Inuit inhabited areas compared to non-Inuit inhabited areas [110]. Due to the relatively low frequency of infant mortality, small misclassification errors in the numerator can have significant impacts on the rate. We demonstrate this in the following example:

We first assume that the actual Indigenous IMR for a given Indigenous population in Canada is 10 per 1000. We base this assumption on the fact that the overall IMR for Canada ranged from 4.9 and 5.4 per 1,000 live births between 2000 and 2009 (perinatal health indicators 2013) and the peer reviewed literature cited above, which suggests Indigenous IMR rates are 1.9 to 3.6 higher than comparator rates. We next assume that misclassification of Indigenous infants as non-Indigenous infants on the infant death certificate is $25 \%$ and that misclassification of non-Indigenous infants as Indigenous infants is $1 \%$, drawing on the Arias study. We further assume that the rate of misclassification of Indigenous infants as non-Indigenous infants on the birth registration is smaller than that of the death registration $(5 \%)$, taking into account that it is the parents who complete the birth certificate, but usually health care providers, often in a tertiary care setting outside of the infant's home community, who complete the death certificate. Finally we as- 
sume that misclassification of non-Indigenous infants as Indigenous is also very small $(1 \%)$, that no additional sources of Indigenous ethnicity apart from the birth registration are being used, and that a cross-sectional method is being used to calculate the IMR instead of the gold standard cohort method, which by linking birth and death certification allows some correction of misclassification on the death certificate drawing on the birth certificate.

The calculated Indigenous Ratio

$\mathrm{R} 1=(X-a+b) /(Y-c+d)=(10-2.5+$ $0.1) /(1000-50+10)=7.6 / 960=7.9 / 1000$

In this case, the calculated Indigenous mortality rate is over $20 \%$ lower than the actual Indigenous mortality rate - an error that would have striking practical and policy implications.

\subsection{Over-reliance on single registry linkage}

As a result of the missing and/or inconsistent Indigenous identifiers in Canada's core health data sources, there is subsequent over-reliance on linkages to a single registry of a sub-population of Indigenous people (for example the registry of persons who are recognized by the federal government as having "Indian status" according to the Indian Act or the registry of Métis people held by a provincial Métis organization) in order to determine core population health indicators such including health determinants, disease incidence and prevalence rates, mortality rates, and health care access rates. Despite efforts to refine these methods [97], there are several consequent problems with this situation. Firstly, large proportions of the total Indigenous population are excluded from the Indigenous rate or ratio calculation. Indigenous persons may be excluded from the registry population either because they do not fit the inclusion criteria of the registry (for example a self-identified First Nations or Indian person who is does not meet the Indian Act definitions of "Status Indian") or because the registry is incomplete (for example a First Nations child living in an urban area who does meet the criteria for registration as a Status Indian but whose family/caregivers have not yet gone through the typically multi-step administrative processes to have them registered, or a Métis person who choses for personal or political reasons not to join their provincial Métis organization). This problem of exclusion is compounded by the fact that excluded Indigenous persons are usually misclassified as part of the "non-Indigenous" comparison population. The sec- ond big challenge with the over-reliance on linkage use to identify Indigenous peoples in datasets in Canada is that there is a limited ability to estimate the degree of misclassification of Indigenous persons and events as non-Indigenous and vice versa because in contrast to Australia, the United States, and New Zealand, there is typically only one source of Indigenous identity data in these linked health datasets. This situation is methodologically suboptimal, and we will demonstrate below how it commonly results in an underestimate of Indigenous disease burden.

For example, the three CMAJ publications [75-77] discussed in Section 3 above all relied on a crosslinkage between federal Indian registration records as defined by the Indian Act with provincial health databases to identity the Indigenous cohort which was subsequently compared to a "non-Indigenous" cohort that included the remaining provincial Indigenous population (i.e. Indigenous people not identified in federal Indian registration records). In their study of access to angiography for First Nations people in Alberta, Bresee et al. acknowledge that this Indian registration definition of Indigenous people represents only $81 \%$ of self-identified First Nations people and 53\% of the total Indigenous population in Canada. They further note that all of the Indigenous people in the province of Alberta not registered under the Indian Act were included in the "non-First Nations" comparison group [77]. There is good evidence that challenges in accessing urgent medical care cut across Indigenous sub-populations [11111] and disparities in access to invasive and life-saving cardiac procedures have also been demonstrated for Indigenous populations in Australia and New Zealand [112]. If one assumes that non-Status First Nations/Indian, Métis, and Inuit populations in Alberta also experience disparities in access to angiography following acute MI compared to non-Indigenous persons, then inclusion of these populations in the "non-First Nations" group would reduce the magnitude of the odds ratio demonstrating that First Nations patients are less likely to receive angiography compared to an odds ratio calculated using a comparison group in which all Indigenous people had been excluded.

In contrast to the striking and policy relevant impacts of misclassification in the infant mortality example above, an analysis of this study of relative access to coronary angiography within one day of myocardial infarction [77], suggests a much more modest impact of Indigenous misclassification. While we don't have access to the data to review the adjusted logistic re- 
gression, the authors report that $26.3 \%$ of First Nations patients with MI $(n=1043)$ and $34.7 \%$ of non-First Nations patients ( $n=45721$ ) respectively underwent coronary angiography within one day of myocardial infarction. The crude relative risk of coronary angiography for First Nations compared to non-First Nations patients is therefore 0.758 . To estimate the impact of including non-status First Nations, Métis, and Inuit in the non-First Nations group, we could conservatively assume that the size of the non-status First Nations, Métis, and Inuit population in Alberta is equal to that of the status First Nations population (drawing on the author's acknowledgement that the status First Nations population represents $53 \%$ of the Indigenous population in Canada) and that this population is equally likely to receive angiography within the first day of MI as the status First Nations population. We can assume that misclassification of non-Indigenous people in Alberta as status Indians is close to zero based on the complexity of Indian registration processes. The Indigenous rate of receiving angiography within the first day of MI would remain the same $(26.3 \%)$ under these assumptions. The non-Indigenous rate would change slightly, as there would now be both a smaller numerator and denominator. From the numerator we would subtract the number of Indigenous events misclassified as non-Indigenous and from the denominator we would subtract the number of Indigenous people misclassified as non-Indigenous in the total sample. We have set the denominator adjustment as equal to the number of status First Nations in the study (1043). For the numerator adjustment, we have assumed that the misclassified Indigenous population will have the same rate of angiography as the status First Nations population, so the adjustment figure is $1043 * 0.263=274$. The original numerator for the non-Indigenous one day angiography rate is $45721 * 0.347=15,865$. We can now calculate the new non-Indigenous rate, adjusted for Indigenous to non-Indigenous misclassification:

(Original est. of non-Ind. event - est. of Ind.s events misclassified as non-Ind.) (Original est./ of non-Ind. Pop. - est. of Ind. pop misclassified as non-Ind.

$=(15,865-274) /(45721-1043)=15591 / 44678$ $=0.349=34.9 \%$

The revised crude relative risk of getting angiography one day post MI for Indigenous compared to nonIndigenous people is therefore 0.754 compared to the original estimate of 0.758 , a very modest effect indeed - but still an underestimate.

\subsection{Using geography as a proxy for Indigenous identity}

The use of geographic proxy for Indigenous identity has emerged in Canada over the past decade as an alternative to registry data linkage as a method of determining population based estimates of Indigenous health, including mortality, given the absence of Indigenous identifiers in core data sources such as the death certificate [98 113]. In this method, Indigenous identity data collected by the 2006 and earlier censuses is sorted at small geographic levels (i.e. census subdivision or the even smaller census dissemination area) according to the percentage of the total Indigenous subpopulation of interest that self-identified as a member of this population. A "threshold" is then set to categorize small geographic areas as "Indigenous" if the Indigenous subpopulation of interest comprised a specific percentage or more of the total population. In Wilkins et al.'s study of Inuit mortality this threshold was set to at least $33 \%$ Inuit and the comparison population for mortality was all of Canada [113]. In a recent study of First Nations child mortality the cut off was the top one third of census dissemination areas ranked according to Indigenous identity and the comparison population excluded these regions [98]. Mortality rates for both studies were determined by linking the postal code on the death certificate to the geocoded datasets [98 113].

In both of these studies, the calculated Indigenous mortality rates are in fact a blending of Indigenous specific mortality rates and non-Indigenous mortality rates for the high proportion Indigenous identity regions. For example, $15 \%$ of the population in the "Inuit inhabited areas" in the Inuit mortality study and 5\% of the population in the "high percentage First Nations area" in the First Nations child mortality study are of non-Indigenous identity. If we assume that Indigenous mortality rates are higher than non-Indigenous mortality rates in these regions (which is supported by the findings of these studies) then logically it follows that this combining of Indigenous and non-Indigenous rates in this method will invariably result in an underestimate of the true Indigenous rate. This problem is exacerbated by the fact that the comparison populations (the general Canadian population in the Inuit mortality study and the low percentage Indigenous areas in the second study) each contain large numbers of Indigenous peoples, which using the same logic will erroneously elevate the non-Indigenous comparison rates, resulting in a further reduction in the absolute and relative Indigenous/non-Indigenous mortality risk calcula- 
tions. Additional limitations of this method include the fact that it is ecological and less useful in modelling determinants of Indigenous/non-Indigenous mortality disparities and that its ongoing use will be limited by absence of reliable Indigenous population estimates at the census subdivision and smaller geographic level with the move of the Indigenous identity question from the census to the NHS in 2011.

\subsection{Non-response bias and sampling error in the Census, NHS, and other survey datasets}

Non-response bias arises when persons who do not participate in a survey have different characteristics than survey participants and as a result reported estimates do not represent the true population values. As discussed in 4.2, non-participation of Indigenous people in the 2001 and 2006 census included block non-participation by multiple First Nations on-reserve communities, a disproportionate number of highly mobile and homeless Indigenous individuals, individuals who do not have the assumed literacy skills required to complete the census, and Indigenous people who chose not to participate based for person or political reasons. Housing instability (as reflected by homelessness and high mobility) and lower literacy skills are associated with poverty and an increased burden of illness [14]. It would therefore follow that if there are higher rates of non-participation in the census for Indigenous persons experiencing housing instability and/or lower literacy skills than for Indigenous persons who do not experience these things, that census data will underestimate Indigenous health and social disadvantage. In addition to non-response bias, survey non-response also causes increased sampling error due to the reduced number of participants contributing to the sample [114]. This in turn results in a decrease in the precision of estimates, which will be particularly important at the small area level.

Until recently the census was considered the "gold standard" for Indigenous population enumeration and there was no way of estimating the impact of census non-response bias on estimates of Indigenous health and social disadvantage. The Our Health Counts Urban Aboriginal Health (OHC) study partially addresses this gap through the rigorous and successful use of respondent driven sampling (RDS), which is known to effectively engage populations that may be missed by the census, including persons who are homeless, highly transient, or have low literacy skills. The urban First Nations arm of this study demonstrated strik- ing levels of poverty among self-identified First Nations residents of the city of Hamilton, that were much higher than comparable estimates of poverty for urban Indigenous populations emerging from the 2006 census [115]. For example, according to the OHC study, $78.2 \%$ of First Nations persons living in Hamilton earn less than $\$ 20,000$ per year. The $\mathrm{OHC}$ income data may be more representative of the actual income profile of the First Nations population in Hamilton than the 2006 Census as the RDS method is validated and adjusted for bias post-survey using RDS statistics and the RDS study successfully engaged highly mobile and homeless First Nations individuals. For example the OHC First Nations study found that $13 \%$ of the adult First Nations population in Hamilton described themselves as homeless or in transition - the large majority of whom would have been missed by census enumerators. Further validation of the low income data in the OHC First Nations study is provided by RDSadjusted income quintile data generated by a linkage to census income quintile neighbourhood level data , which revealed that over $70 \%$ of the First Nations population in Hamilton lived in the lowest income quartile neighbourhoods compared with $25 \%$ of the general Hamilton population and $20 \%$ of the Ontario population [115]. The Inuit arm of this study found a similar striking and previously undocumented socioeconomic and health status burden for the Inuit of Ottawa and a participation rate of only $18 \%$ in the 2006 census [84].

Non-response errors, including non-response bias and a decrease in the precision of small area estimates are even more problematic in the voluntary NHS, which had a markedly reduced unweighted response rate compared to the 2006 long form census $(69.3 \%$ compared to $93.5 \%$ ). Since there were no Indigenous identifiers on the 2011 census, we cannot directly determine Indigenous specific NHS non-response rates or study non-response bias. Urgently required follow-up studies include a release of NHS non-response rates for First Nations on-reserve 2011 census enumeration areas (which are known to be primarily inhabited by First Nations people) and studies that examine the characteristics of Indigenous NHS 2011 responders and nonresponders by linking to the 2006 Census long form. Additional urban RDS studies are also in progress which will allow an opportunity to examine the selfreported prevalence of 2011 NHS non-response and provide a comparison dataset for 2011 NHS estimates of urban Indigenous health and social disparities. At this point it is clear that non-response on the NHS has definitely reduced the ability of Statistics Canada to 
provide much needed smaller area health and social statistics for Indigenous peoples in Canada.

National health and social surveys administered by Statistics Canada, such as the Aboriginal Peoples Survey, the Canadian Maternity Experiences Survey and the Canadian Community Health Survey are subject to non-response bias and sampling error derived from their sampling frame, which are the census for 2006 and earlier and subsequently the NHS. While we are not able to quantify with precision, based on the discussion above it appears that the sample of Indigenous persons who responded to the 2006 census may experience significant socioeconomic advantaged compared to the total Indigenous population in Canada and that this bias is exacerbated in the 2011 NHS. With respect to sampling error, the 2006 census sampling frame was already inadequately powered to provide precise estimates at the sub-provincial/territorial level disaggregated by Indigenous subpopulation (i.e. First Nations with status, First Nations/Indian without status, Inuit, and Métis) due to the fact that the long form census with the Indigenous identity question was only administered to $20 \%$ of the total population and that some post-census surveys occurred simultaneously and required distinct samples to avoid survey fatigue. The dramatically reduced response rate in the 2011 NHS again exacerbates this under-powering with respect to its use as a sampling frame to national surveys.

With the exception of the First Nations Regional Longitudinal Health Survey, which is able to use lists of Indigenous persons living in the participant First Nations on-reserve communities as it sampling frame and the RDS studies described above, research and policy makers wishing to conduct additional health and social surveys of Indigenous populations are forced to use convenience sampling because there is no suitable and accessible sampling frame for the specific Indigenous subpopulations with whom the surveys are being conducted. For example both the Urban Aboriginal Peoples Study (UAPS) [116] and the Toronto Aboriginal Research Project (TARP) [117] used convenience recruitment strategies. The former attempted to recruit a population representing some diversity with respect to socioeconomic position by stratifying convenience recruitment by socioeconomic position and setting recruitment goals with respect to persons experiencing socioeconomic disadvantage, however based on what is known about recruitment bias using convenience sampling it can be assumed that within specific socioeconomic strata, persons who choose to participate in a survey are different than those who choose to not par- ticipate, with the former group likely experiencing relative socioeconomic, literacy, and housing advantage compared to the latter [118]. As a result of recruitment bias based on the convenience sampling method, both studies almost certainly under-represented urban Aboriginal health and social disadvantage.

\subsection{Under-reporting of methodologic limitations and their consequences in the published literature}

In this section, we have systematically examined the core data sources and methods used to produce estimates of Indigenous health determinants, health status and health care access in Canada. We have demonstrated that as a result of deficiencies in the core data sources with respect to Indigenous identification and the subsequent need to use supplementary methods to determine Indigenous identity there is almost uniformly error in derived measures of Indigenous health and that these errors systematically tend towards the underestimate of Indigenous health and social inequities.

There are several arising and relatively urgent discussion points. Firstly, the substantive efforts of statisticians and researchers currently working to achieve Indigenous health statistics in the face of existing source data infrastructure deficiencies in Canada are admirable and the purpose of this critical review is not to undermine their achievements. It is critical however, that this work be accompanied by full and transparent disclosure of the limitations of data sources and methods, with accompanying attempts to understand the impacts of these limitations on the precision and relative magnitude of the estimated health outcome measures. Of concern is that review of the literature indicates that this type of disclosure is the exception rather than the norm. For example, in contrast to Australia, New Zealand, and the United States, the literature regarding the impacts of Indigenous/non-Indigenous misclassification on Indigenous health assessment is almost nonexistent in Canada. In Indigenous health publications and reports drawing on data linkages with Indigenous registries, limitations such as the restriction of the Indigenous population to First Nations persons with status or registered Métis are commonly given only superficial mention near the end of the article, with little discussion of the potential impacts, if at all [75-77/119]. The NHS Aboriginal statistics releases and accompanying technical reports do not transparently identify the loss of Indigenous statistics released at the smaller regional level, despite the fact that this will have huge 
negative impacts on Indigenous health service planning and delivery. In the Urban Aboriginal Peoples Study report, which was widely publicized, there is no discussion in the main study report of the recruitment bias which was almost certainly built into the convenience sample method despite efforts to force representation through the use of quotas [116].

Finally, and most importantly, is the arising recommendation that the focus needs to shift from further development of compensatory methods to overcome gaps in Indigenous identification in core health data sources towards - what is urgently needed - a focus on working in partnership with Indigenous leaders and communities to build in meaningful and relevant Indigenous self-identification into the source datasets themselves. We hope that this section has demonstrated that to do otherwise will result in a continued (and at this time progressive) masking of Indigenous health and social inequity in Canada.

\section{Moving forward}

In this paper, we have offered a critical documentation of the current state of Indigenous health statistics in Canada. We provided an overview of the policy and jurisdictional landscape, including current ethical, legal and practical rationale for Indigenous governance and management of Indigenous health and social information. Subsequently, we detailed the deficits in Indigenous identification in Canada's core population health data sources and demonstrated how these deficiencies contribute to a masking of Indigenous health and social inequities.

Our aim was to expose the two central and interconnected roots of Indigenous health information deficiencies in Canada: the lack of culturally relevant, consistent and inclusive Indigenous identifiers in source datasets and the need to actively engage Indigenous peoples in meaningful partnerships to govern and manage data that is collected from them.

We applaud and continue to learn from the dedicated efforts of the small cadres of Indigenous community leaders, governmental scientists and academics in Canada who are working to bridge existing infrastructure gaps [97]. However, the time is long overdue to recognize and address what we perceive as the elephants in the room. There will be little true progress until there is a shifting of efforts towards Indigenous data partnerships and the establishment of relevant, consistent and inclusive Indigenous identifiers in Canada's source health datasets.
In each section of this paper, we have included strategies and exemplars for moving forward. These domestic and international models demonstrate that it is possible to work in partnership with Indigenous community representatives to build Indigenous health databases that are both relevant and statistically sound. While at times the challenges may seem numerous, it can be done, provided there is scholarly, policy and political will. There is a relative urgency to this work currently, as a result of these critical gaps in health assessment, Indigenous people in Canada experience not only a disproportionate burden of illness and premature death, but also a double standard with respect to population level documentation of and subsequent appropriate public health response to this burden. This unacceptable situation is in tension not only with Canada's otherwise excellent statistical track record, but also with the UN Fundamental Principles of Official Statistics [120] - which require official statistics to be practically useful and impartially compiled and made available. We must work together for change.

\section{Acknowledgements}

Dr. Smylie would like to acknowledge the mentorship and collegial support she has received as a member of the Centre for Research on Inner City Health, the Canadian Perinatal Surveillance System, Public Health Agency of Canada; the Vital Statistics Council of Canada, Statistics Canada; and the International Group for Indigenous Health Measurement. Dr. Smylie is currently funded by a CIHR Applied Public Health Research Chair in Indigenous Health Knowledge and Information.

\section{References}

[1] J. Smylie, Indigenous Child Well-Being in Canada, in Encyclopedia of Quality of Life and Well-Being, A. C. Michalos, Ed. Toronto, ON: Springer, 2014.

[2] P.W. Setel, S.B. Macfarlane, S. Szreter, L. Mikkelsen, P. Jha, S. Stout and C. AbouZahr, A scandal of invisibility: making everyone count by counting everyone., Nov. 2007.

[3] National Conference of State Legislatures, Health Cost Containment and Efficiencies: Public Health and Cost Savings, Washington D.C., 2011.

[4] S. Dahrouge, R. Devlin, B. Hogg, G. Russel, D. Coyle and D. Fergusson, The Economic Impact of Improvements in Primary Healthcare Performance, Ottawa, ON, 2012.

[5] E. Tamm, T. Kivisild, M. Reidla, M. Metspalu, D.G. Smith, C.J. Mulligan, C.M. Bravi, O. Rickards, C. Martinezlabarga, E.K. Khusnutdinova, S.A. Fedorova, M.V. Gol- 
ubenko, V.A. Stepanov, M.A. Gubina, S. Zhadanov, L. Ossipova, L. Damba, M. Voevoda, J. Dipierri, R. Villems and R. Malhi, Beringian Standstill and Spread of Native American Founders, Nativ Am mtDNAs (9) (2007), 1-6.

[6] Parks Canada, Unearthing the Law: Introduction, Government of Canada, 2009. [Online]. Available: http://www. pc.gc.ca/eng/docs/r/pfa-fap/sec1.aspx.

[7] D. Nettle, Linguistic diversity of the Americas can be reconciled with a recent colonization, Proc Natl Acad Sci USA 96(6) (1999), 3325-3329.

[8] Royal Commission on Aboriginal Peoples (RCAP), Part One: The Relationship in Historical Perspective, vol. 1, no. Looking Forward Looking Back, 1996, pp. 36-46.

[9] Royal Commission on Aboriginal Peoples (RCAP), Stage Three: Displacement and Assimilation, vol. 1, no. Looking Forward Looking Back, 1996, pp. 130-185.

[10] M. King, A. Smith and M. Gracey, Indigenous health part 2: the underlying causes of the health gap, Lancet 374(9683) (Jul 2009), 76-85.

[11] B. Allan and J. Smylie, First Peoples, second class treatment: The role of racism in the health and well-being of Indigenous peoples in Canada, Wellesley Inst.

[12] J. Smylie, Aboriginal infant mortality rate in Canada, Lancet 380 (20 October 2012), 1384.

[13] S.B. Harris, O. Bhattacharyya, R. Dyck, M.N. Hayward and E.L. Toth, Type 2 diabetes in Aboriginal peoples, Can J Diabetes 37(Suppl 1 Apr. 2013), pp. S191-6.

[14] C. Loppie Reading and F. Wien, Health Inequalities and Social Determinants of Aboriginal Peoples, Health, 2009.

[15] Statistics Canada, National Household Survey (NHS) Aboriginal Population Profile, Ottawa, 2013.

[16] Statistics Canada, 2006 Census of Population, Dec. 2010.

[17] Statistics Canada, 2006 Short Census Questionnaire, Ottawa, 2006.

[18] R. Collier, Long-form census change worries health researchers, Can Med Assoc J 182(12) (Sep. 2010), E563-4.

[19] Statistics Canada, Chapter 6 - Data dissemination for NHS standard products, Government of Canada, 2011. [Online]. Available: http://www12.statcan.gc.ca/nhs-enm/2011/ ref/nhs-enm_guide/guide_5-eng.cfm.

[20] Statistics Canada, Aboriginal Peoples Survey (APS): Data Sources and Methodology, Statistics Canada, 2012. [Online]. Available: http://www23.statcan.gc.ca/imdb/p2SV.pl? Function=getSurvey $\&$ SDDS $=3250 \&$ lang $=$ en $\& d b=i m d b \&$ $\operatorname{adm}=8 \&$ dis $=2 \#$ a 2 .

[21] Government of Canada, Canada Health Act, 2014.

[22] Statistics Canada, Health in Canada: Welcome to the Vital Statistics Council for Canada, Statistics Canada, 2013. [Online]. Available: http://www.statcan.gc.ca/health-sante/ vital/vscc-csecc-eng.htm.

[23] Canadian Institute for Health Information, Data and Standards, Canadian Institute for Health Information, 2014. [Online]. Available: http://www.cihi.ca/CIHI-ext-portal/internet /EN/Theme/standards+and+data+submission/cihi010687.

[24] Public Health Agency Of Canada, Canadian Perinatal Health Report, Ottawa, Ontario, 2008.

[25] Institute of Clinical and Evaluative Sciences, ICES Data. [Online]. Available: http://www.ices.on.ca/Data-andPrivacy/ICES-data. [Accessed: 28-Aug-2014].

[26] Canada Health Infoway, About Infoway: Transforming health care in Canada through health information technology, Canada Health Infoway, 2014. [Online]. Available: https://www.infoway-inforoute.ca/index.php/about-infoway.
[27] Government of Canada, The Constitution Act, Canada, 1982.

[28] J. Ball and P. Janyst, Enacting Research Ethics in Partnerships with Indigenous Communities in Canada: 'Do it in a Good Way,' J Emperical Res Hum Res Ethics An Int J 3(2) (2014), 33-51.

[29] C. Fletcher, Community-based participatory research relations with Aboriginal communities in Canada: An overview of context and process, Pimatisiwin A J Aborig Indig Community Heal 1(1) (2003), 28-62.

[30] M. Ferreira and F. Gendron, Community-based participatory research with traditional and indigenous communities of the Americas: Historical context and future directions, Int J Crit Pedagog 3(3) (2011), 153-68.

[31] Inuit Tapiriit Kanatami and Nunavut Research Intitute, Negotiating Research Relationships: A Guide for Communities, 2007.

[32] B. Elias, J. O'Neil and D. Sanderson, The politics of trust and participation: A case study of building university and community capacity to develop health information systems in a First Nations context, J Aborig Heal 1(1) (2004), 68-80.

[33] National Aboriginal Health Organization (NAHO), Ways of Knowing: A Framework for Health Research, National Aboriginal Health Organization, 2003.

[34] United Nations Permanent Forum on Indigenous Peoples, Declaration on the Rights of Indigenous Peoples, United Nations, 2007. [Online]. Available: http://www.undesadspd. org/IndigenousPeoples/DeclarationontheRightsofIndigenous Peoples.aspx.

[35] United Nations, United Nations Declaration on the Rights of Indigenous Peoples, 2008.

[36] Indian and Northern Affairs, Report of the Royal Commission on Aboriginal Peoples (RCAP), 1996.

[37] I. Mosby, Administering Colonial Science: Nutrition Research and Human Biomedical Experimentation in Aboriginal Communities and Residential Schools, 1942-1952, Soc Hist 46(91) (2013), 145-172.

[38] D. Harry and M. Kanehe, Asserting Tribal Sovereignty over Cultural Property: Moving Towards Protection of Genetic Material and Indigenous Knowledge, Seattle J Soc Justice 5(1) (2006).

[39] Health Council of Canada, The Health Status of Canada's First Nations, Métis, and Inuit Peoples, 2005.

[40] J. Smylie, N. Kaplan-Myrth and K. McShane, Indigenous knowledge translation: baseline findings in a qualitative study of the pathways of health knowledge in three indigenous communities in Canada, Health Promot Pract 10(3) (Jul. 2009), 436-46.

[41] Urban Aboriginal Task Force, Urban Aboriginal Task Force: Final Report, 2007.

[42] Y. Boyer, Aboriginal Health: A Constitutional Rights Analysis, 2003.

[43] Y. Boyer, First Nations, Métis and Inuit Health Care: The Crown's Fiduciary Obligation, 2004.

[44] Aboriginal Affairs and Northern Development, Aboriginal Consultation and Accommodation, 2011.

[45] M. Coon Come, Canada sets lowest standard at World Conference on Indigenous Peoples, CBC news, 27-Sep-2014.

[46] I.T. Kanatami and N.R. Institute, Negotiating Research Relationships: A Guide for Communities, 2007.

[47] A. of F. Nations, First Nations Regional Longitudinal Health Survey: Code of Research Ethics, 2007.

[48] P. Martens, J. Bartlett, E. Buland and E. Al, Profile of Métis Health Status and Healthcare Utilization in Manitoba: A 
Population-based Study, Univ. Manitoba, Cent. Heal. Policy Collab. with Manitoba Métis Fed., 2010.

[49] Canadian Institutes of Health Research, Natural Sciences and Engineering Research Council of Canada, and Social Sciences and Humanities Research Council of Canada, TriCouncil Policy Statement: Ethical Conduct for Research Involving Humans, 2010.

[50] Canadian Institute for Health Research, Guidelines for Health Research Involving Aboriginal People, CIHR, Ottawa, 2007.

[51] J. Smylie, I. Anderson, M. Ratima, S. Crengle and M. Anderson, Indigenous health performance measurement systems in Canada, Australia, and New Zealand, Lancet 367(9527) (Jun. 2006), 2029-31.

[52] M.J. Anderson and J.K. Smylie, Performance Measurement Systems in Canada: How Well do They Perform in First Nations, Inuit, and Métis Contexts?, Pimatisiwin A J Aborig Indig Community Heal 7(1) (Jan. 2009), 99-115.

[53] J. Smylie, A. Lofters, M. Firestone and P. O'Campo, Population-Based Data and Community Empowerment, in: Rethinking Social Epidemiology: Towards a Science of Change, O. P. and D. J., eds, Springer Publishing Company, 2011.

[54] A. Pinto and J. Smylie, Indigenous Health and Ethics: Lessons for Global Health, in An Introduction to Global Health Ethics, 2013, p. 73.

[55] J. Smylie, M. Firestone, L. Cochran, C. Prince, S. Maracle, M. Morley, S. Mayo and M. Spiller, Our Health Counts urban Aboriginal Health Database Project: Community Report, 2011.

[56] M. Firestone, J. Smylie, S. Maracle, C. Siedule and L. Pigeau, De dwa da dehs ney>s Aboriginal Health Access Centre, Tungasuvvingat Inuit Family Health Team, Metis Nation of Ontario, and P. O'Campo, Concept Mapping: Application of a Community-Based Methodology in three Urban Aboriginal Populations, Am Indian Cult Res J 38(4) (2014).

[57] First Nations Health Authority, Health through Wellness: Governance and Accountability, First Nations Health Authority, 2013. [Online]. Available: http://www.fnha.ca/about /governance-and-accountability.

[58] First Nations Health Council, British Columbia Tripartite Framework Agreement on First Nation Health Governance, British Columbia, 2011.

[59] J. Carjuzaa and K. Fenimore-Smith, The Give Away Spirit: Reaching a Shared Vision of Ethical Indigenous Research Relationships, J Educ Controv 5(2) (2010).

[60] V.J. Kirkness and R. Barnhardt, First Nations and Higher Education: The Four R's - Respect, Relevance, Reciprocity, Responsibility, J Am Indian Educ 30(3) (1991), 1-15.

[61] J.A. Makokis, Nehiyaw iskwew kiskinowâtasinahikewina paminisowin namôya tipeyimisowin; Cree Women Learning Self Determination Through Sacred Teachings of the Creator, 2008.

[62] R. Dufour, Public Hearing Discussion Paper 2: Focusing the Dialogue, 1993.

[63] J. O'Neil, J. Reading and A. Leader, Changing the Relations of Surveillance: The Development of a Discourse of Resistance in Aboriginal Epidemiology, Hum Organ 57(2) (1998).

[64] M.-E. Kelm, Colonizing Bodies: Aboriginal Health and Healing in British Columbia 1900-50. UBC Press, 1998.

[65] Inuit Knowledge Centre, Naasautit: Inuit Health Statistics, Inuit Knowledge Centre, 2011. [Online]. Available: http:// www.inuitknowledge.ca/naasautit.
[66] P. Hutchinson, M. Evans and C. Reid, Report on the Statistical Description and Analysis of the 2006 metis nation of British Columbia Provincial Survey, 2007.

[67] Métis Nation Saskatchewan, First-Ever Saskatchewan Métis Health Survey, Saskatchewan, 2013.

[68] J. Smylie, S. Crengle, J. Freenantle and M. Taualii, Indigenous Birth Outcomes in Australia, Canada, New Zealand and the United States, Open J Womens' Heal 4 (2010), 7-17.

[69] M. Ratima, W. Edwards, S. Crengle, J. Smylie and I. Anderson, Maori health indicators: A background paper for the project'action oriented indicators of health and health systems development for Indigenous peoples in Canada, Australia, and New Zealand,' Saskatoon, 2006

[70] Statistics Canada, Aboriginal Children's Survey (ACS), Statistics Canada, 2008. [Online]. Available: http://www23. statcan.gc.ca/imdb/p2SV.pl?Function=getSurvey\&SDDS= 5108.

[71] G. Egeland, Inuit Health Survey 2007-2008, Nunatsiavut, 2008

[72] J. Smylie, M. Firestone, Y. Allard, J. Demeria, C. Prince and M. Spiller, Our Health Counts Urban Aboriginal Health Database Project Community Report: Métis Adults, City of Ottawa, Ottawa, 2012.

[73] Assembly of First Nations, First Nations Regional Longitudinal Health Survey (RHS) 2002/03: Results for Adult, Youth and Children Living in First Nations Communities, Ottawa, 2007.

[74] J. Dumont, Cultural framework february 2005 first nations regional longitudinal health survey (RHS): Cultural Framework, Vancouver, BC, 2005.

[75] S. Samuel, L. Palacios-Derflingher, M. Tonelli, B. Manns, L. Crowshoe, S. Ahmed, N. Saad and B. Hemmelgarn, Association between First Nations ethnicity and progression to kidney failure by presence and severity of albuminuria, CMAJ 186(2) (Feb. 2014), 103-109.

[76] Y. Jiang, N. Osgood, H. Lim, M. Stang and R. Dyck, Differential mortality and the excress burden of end-stage renal disease among First Nations peoples with diabetes mellitus: a competing-risks analysis, C Can Med Assoc J 186(2) (Feb. 2014), E86-E94.

[77] L. Bresee, M. Knudtson, J. Zhang, L. Crowshoe, S. Ahmed, M. Tonelli, W. Ghali, H. Quan, B. Manns, G. Fabreau and B. Hemmelgarn, Likelihood of coronary angiography among First Nations patients with acute myocardial infarction, $C$ Can Med Assoc J 186(10) (2014), 372-380.

[78] Statistics Canada, Censuses of Canada 1665 to 1871: Aboriginal peoples, Government of Canada, 2014. [Online]. Available: http://www.statcan.gc.ca/pub/98-187-x/4151278eng.htm.

[79] G. Goldmann and A. Siggner, Statistical concepts of Aboriginal people and factors affecting the counts in the census and the Aboriginal peoples survey, Ottawa, 1995.

[80] J.C. Saku, Aboriginal Census Data in Canada: A Reserach Note, Can J Native Stud XIX(2) (1999), 365-379.

[81] Statistics Canada, Incompletely enumerated Indian reserves and Indian settlements, 2013. [Online]. Available: http://www12.statcan.gc.ca/census-recensement/2011/ref/ aboriginal-autochtones-eng.cfm. [Accessed: 28-Aug-2014].

[82] M. Anderson, J. Smylie, I. Anderson, R. Sinclair and S. Crengle, First Nations, Metis, and Inuit health indicators in Canada: a background paper for the project 'action oriented indicators of health and health systems development for Indigenous peoples in Canada, Australia, and New Zealand,' Saskatoon, 2006. 
[83] Statistics Canada, Aboriginal Peoples in Canada in 2006: Inuit, Métis and First Nations, 2006 Census, 2008.

[84] J.K. Smylie, C. Siedule, M. Firestone, K.E. Mcshane, M. Spiller and Tungasuvvingat Inuit Family Health Team, Our Health Counts - Population based measures of urban Inuit health determinants, health status, and health care access, PLoS Med Under Rev.

[85] M. Firestone, J.K. Smylie, M. Spiller, K.E. Mcshane, C. Prince, M. Yu and C. Siedule, Our Health Counts Urban Aboriginal Health Project Draft Community Report: Inuit Adults, City of Ottawa, 2012.

[86] Statistics Canada, National Household Survey (NHS) User Guide, 2011.

[87] Statistics Canada, Aboriginal Peoples Reference Guide, National Household Survey 2011, 2011.

[88] Statistics Canada, NHS Aboriginal Population Profiles, 2011. [Online]. Available: http://www12.statcan.gc.ca/nhsenm/2011/dp-pd/aprof/index.cfm?Lang=E.

[89] Statistics Canada, Canadian Community Health Survey Annual Component: Data Sources and Methodology, 2014. [Online]. Available: http://www23.statcan.gc.ca/imdb/p2SV. pl?Function=getSurvey $\&$ SDDS=3226. [Accessed: 28-Aug2014].

[90] Statistics Canada, National Longitudinal Survey of Children and Youth (NLSCY): Data Sources and Methodology,?2014. [Online]. Available: http://www23.statcan.gc.ca/ $\mathrm{imdb} / \mathrm{p} 2 \mathrm{SV} . \mathrm{pl}$ ?Function=getSurvey $\&$ SDDS=4450. [Accessed: 28-Aug-2014].

[91] Statistics Canada, Maternal Experiences Survey (MES): Data Sources and Methodology, 2014. [Online]. Available: http://www23.statcan.gc.ca/imdb/p2SV.pl?Function=get Survey\&SDDS=5019. [Accessed: 28-Aug-2014].

[92] Statistics Canada, Aboriginal Children's Survey (ACS): Detailed Information for 2006, 2008. [Online]. Available: http: //www23.statcan.gc.ca/imdb/p2SV.pl?Function=getSurvey $\&$ SDDS=5108. [Accessed: 28-Aug-2014].

[93] Canadian Public Health Association, The Impact of Cancelling the Mandatory Long-Form Census on Health, Health Equity and Public Health, 2010.

[94] M. Green, Reporting infant mortality rates for Aboriginal populations in Canada: A jurisdictional review of methodologies, 2007.

[95] M.J. Norris, Aboriginal Languages in Urban Canada: A Decade in Review, 1996-2006, Aborig Policy Stud 1(2) (2011), 4-67.

[96] M.J. Norris, Aboriginal languages in Canada: Emerging trends and perspectives on second language acquisition, 2006.

[97] B. Elias, L. Hart and P. Martens, Just get on with it. Linking data systems to report on infant mortality and the First Nations population in Manitoba (Canada), Stat J IAOS 30 (2014), 285-295.

[98] P.A. Peters, L.N. Oliver and D.E. Kohen, Mortality among children and youth in high-percentage First Nations identity areas, 2000-2002 and 2005-2007, Rural Remote Health 13(3) (Jan. 2013), 2424.

[99] Cancer Care Ontario, Aboriginal Cancer Strategy II Annual Report 2012-2013 Staying on the Path, 2013.

[100] International Working Group on Indigenous Affairs (IWGIA), Who are the Indigenous People. [Online]. Available: http://www.iwgia.org/culture-and-identity/identification-ofindigenous-peoples. [Accessed: 04-Sep-2014].

[101] Statistics New Zealand, Report of the Review of the Measurement of Ethnicity June 2004, 2004.
[102] Statistics New Zealand, Classifications and related statistical standards: Ethnicity. [Online]. Available: http://www.stats. govt.nz/methods/classifications-and-standards/classification -related-stats-standards/ethnicity.aspx. [Accessed: 04-Sep2014].

[103] B. Petry and E. Potts, Measuring indigenous populations across nations: Challenges for methodological alignment, Stat J IAOS 30 (2014), 55-63.

[104] United Nations, Report of the Working Group on the Universal Periodic Review, Isreal, 2013.

[105] P.C. Webster, Aboriginal health programming under siege, critics charge, C Can Med Assoc J 184(14) (Oct. 2012), E739-E740.

[106] E. Arias, W.S. Schauman, K. Eschbach, P.D. Sorlie and E. Backlund, The validity of race and Hispanic origin reporting on death certificates in the United States, Natl Cent Heal Stat Vital Heal Stat 2148 (Oct. 2008), 1-23.

[107] S. J., Aboriginal infant mortality rate in Canada, Lancet 380(9851) (2012), 1384

[108] J. Smylie and M. Anderson, Understanding the health of Indigenous peoples in Canada: Key methodological and conceptual challenges, C Can Med Assoc J 175(6) (Sep. 2006), 602.

[109] J. Smylie, D. Fell and A. Ohlsson, A Review of Aboriginal Infant Mortality Rates in Canada: Striking and Persistent Aboriginal/Non-Aboriginal Inequities, Can J Public Heal 101(2) (2010), 143-148.

[110] Z. Luo, R. Wilkins, M. Heaman, P. Martens, L. Hart, S. Wassimi, F. Simonet, Y. Wu and D. Fraser, William, Neighborhood Socioeconomic Characteristics, Birth Outcomes and Infant Mortality among First Nations and Non-First Nations in Manitoba, Canada, Open Womens Heal J 4 (2010), 55-61.

[111] S. Marrone, Understanding barriers to health care: a review of disparities in health care services among indigenous populations, Int J Circumpolar Health 66(3) (2007).

[112] S. Crengle, J. Freemantle, G. Gallaher, D. McAullay, K.E. Mcshane and M. Taualii, Indigenous Children's Health Report: Health Assessment in Action, 2009.

[113] R. Wilkins, S. Uppal, P. Finès, S. Senécal, É Guimond and R. Dion, Article Life expectancy in the Inuit-inhabited areas of Canada,1989 to 2003, 2008.

[114] Statistics Canada, National Household Survey (NHS) Data Quality and Assessment Indicators. [Online]. Available: http://www12.statcan.gc.ca/nhs-enm/2011/ref/reportsrapports/ap-pa/ch5-eng.cfm. [Accessed: 04-Sep-2014].

[115] M. Firestone, J.K. Smylie, S. Maracle, M. Spiller and P. O'Campo, Unmasking health determinants and health outcomes for urban First Nations using respondent-driven sampling, BMJ Open 4(7) (Jan. 2014), e004978.

[116] E. Institute, Urban Aboriginal Peoples Study Main Report, Environics Institute, 2010

[117] D. McCaskill, K. FitzMaurice and J. Cidro, Toronto Aboriginal Research Project: Final Report, Toronto, ON, 2011.

[118] B.L. Hedt and M. Pagano, Health indicators: Eliminating bias from convenience sampling estimators, Stat Med 30(5) (2011), 560-568.

[119] Métis Nation of Ontario, Chronic Diseases in the Métis Nation of Ontario, Chronic Disease Surveillance Program, Métis Nation of Ontario, Mar. 2012.

[120] The Economic and Social Council of the United Nations, Fundamental Principles of Official Statistics, 2010. [Online]. Available: http://unstats.un.org/unsd/dnss/gp/FP-NewE.pdf. [Accessed: 15-Sep-2014]. 